\title{
$\beta-\mathrm{FeSi}_{2}$ の熱電特性に及ぼす $\mathrm{MG}$ の効果
}

\author{
永井宏的，飯田 純生放2 \\ 勝山茂江，真島一彦放1 \\ 的大阪大学工学部材料物性工学科, $\overline{\mathbf{T}} 565$ 吹田市山田丘2-1.

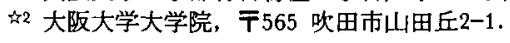

\section{Effect of Mechanical Grinding on the Thermoelectric Properties of $\beta-\mathrm{FeSi}_{2}$}

\author{
Hiroshi Nagai ${ }^{\natural 1}$, Sumio Iida ${ }^{\downarrow 2}$ \\ Shigeru Katsuyama ${ }^{\text {列 }}$ and Kazuhiko Majima \\ t1 Department of Materials Science and Engineering, Osaka University, 2-1 Yamadaoka, Suita 565 \\ \$2 Graduate School, Osaka University, 2-1 Yamadaoka, Suita 565.
}

Received January 11, 1994

The thermoclectric properties of $\beta-\mathrm{FeSi}_{2}$ consolidated by hot pressing of the mechanical grinded (MG) powders were investigated.

Mixture of $\mathrm{Fe}$ and $\mathrm{Si}$ powders was arc-melted in an argon atmosphere to form a button composed of $\alpha-\mathrm{Fe}_{2} \mathrm{Si}_{5}$ and $\varepsilon-\mathrm{FeSi}$ phases. The botton was grinded in a conventional ball-mill for 20-650 hir. The ball-milled powders were hot pressed at $900^{\circ} \mathrm{C}$ for 30 min under $25 \mathrm{MPa}$. X-ray diffraction and EPMA analysis showed that mechanical grinding strongly accelerated the formation of $\beta-\mathrm{FeSi}_{2}$ during hot pressing and small size particles of $\varepsilon$-phase were dispersed in $\beta$ - $\mathrm{FeSi}_{2}$ matrix. The amount of $\varepsilon$-phase increased with increasing MG time. The electrical resistivity $\rho$ significantly decreased with increasing MG time, on the other hand the thermoclectric power $Q$ increased with increasing $M G$ time and reached at a maximum at 100 hr MG time, and thereafter decreased with increasing MG time. As the result, the power factor $Q^{2} / \rho$ was at maximum at $250 \mathrm{hr}$ MG time. Thermal conductivity decreased by about $35 \%$ with increasing M G time up to $500 \mathrm{hr}$, but increased again by annealing at $900^{\circ} \mathrm{C}$.

\section{1 緒言}

最近、熱エネルギーの有效利用や熱源の多梯化 に伴って、熱電材料の利用が注目されており、種ヶ の熱電材料の開発が進められている.1)-6） $\beta$ $\mathrm{FeSi}_{2}$ 系熱電材料についても、その性能を向上させ るため、添加元素の探索など種々の検討がなされて いる。前報でも明らかなように7)、その性能には $\varepsilon$ 相(FeSi)の存在など組織が大きな影響を及ぼすも のと考えられるが、組織が性能に及ぼす影響を検討 した研究は殆どない。本研究では、 $\beta-\mathrm{FeSi}_{2}$ 系 熱電材料開発の基礎的研究として、メカニカルグラ インテング $(\mathrm{M} G)$ を施した粉末をホットプレスす ることによって作製した試料の熱電特性に及ぼすM Gの効果、特に $\varepsilon$ 相の存在の影響について検討した。 


\section{2 实験方法}

本実験では、前報7)で検討した種々のプロセス のうちFig.1に示す方法によって試料を作製した. すなわち、Fe粉末及びSi叛末をFe-66.7at\%Siの制合 で混合、压縮成形したものを、アルゴンアーク淮解 し、鉄製乳鉢でー60メッシュまで粉砕したのち、さ らにボールミルで20〜650 hrMGを施した. MG は通常のステンレス製ボールミルを用いて重量比で ボール:粉末 $=100: 1$ 、回転数120rpmて20〜650 hr 行った. $M G$ を施す前の試料は、前報で示したよう に、 $\alpha$ 相 $\left(\mathrm{Fe}_{2} \mathrm{Si}_{5}\right)$ と $\varepsilon$ 相( $\left.\mathrm{FeSi}\right) の 2$ 相からなってお り、MG時間の増大にともなって、雨相のX線ピー クは著しくブロードになるが、 $\beta$ 相は生成していな い. MGした粉末をカーボン・ダイスを用いて10 $\sim 2 \mathrm{~Pa}$ 以下の真空雾团気中、 $900^{\circ} \mathrm{C} 、 25 \mathrm{MPa}$ で 30 min間ホットプレスして試料を作製した，得られた 試料の相、組織及び組成をXRD、SEMおよびEPMAで分 析し、熱起電力および比抵抗の測定は、前報と同㥞 の方法によってを室温から $800^{\circ} \mathrm{C}$ までアルゴン需围 気中で同時に測定した：また、室温における熱伝導 率をレーザーフラッシュ法によって测定した。

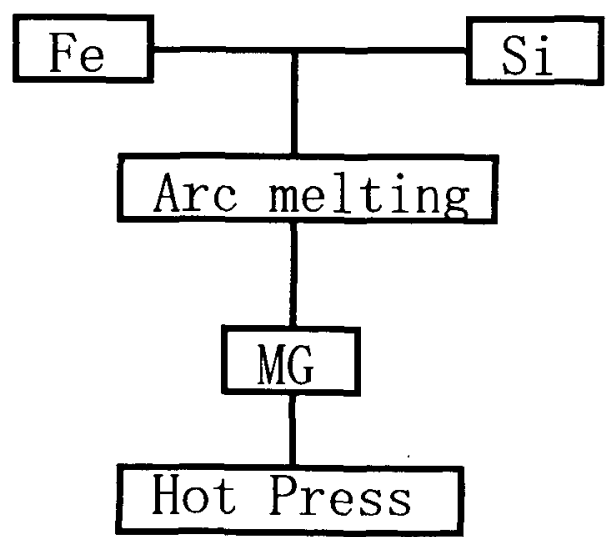

Fig. 1 Preparation process of $\beta$-FeSi 2

\section{3 実験結果及び考察}

Fig. 2にM G 時間の異なる物末を $900^{\circ} \mathrm{C} て ゙ 30 \mathrm{~min}$ ホットプレスした試料のX線回折結果を示す. M G 施した原料粉末は、前述のように、 $\alpha$ 相と $\varepsilon$ 相の 2 相からなっているが、MGしたものは $900^{\circ} \mathrm{C} て ゙ 30 \mathrm{~min}$ のホットプレスだけで殆どが $\beta$ 相化しており、溶 解法で $(\alpha+\varepsilon)$ からなる陚料を作製したものを熱 (a)



(b)



(c)

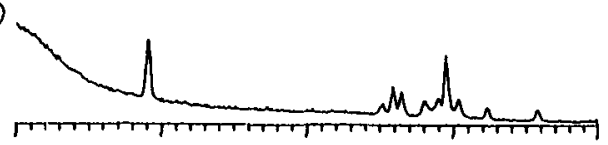

(d)

(e)
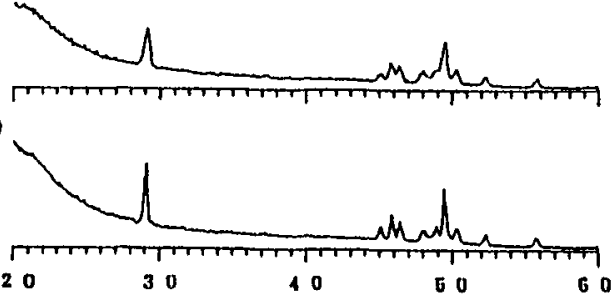

Fig. $2 X$-ray diffraction patterns of $\mathrm{Fe}-$ 66. 7at\%Si samples ball-milled for various hours and hot-pressed at $900^{\circ} \mathrm{C}$ for 30 min.

(a) $20 \mathrm{hr}$, (b) $100 \mathrm{hr}$, (c) $250 \mathrm{hr}$, (d) $500 \mathrm{hr}$, (e) $650 \mathrm{hr}$.

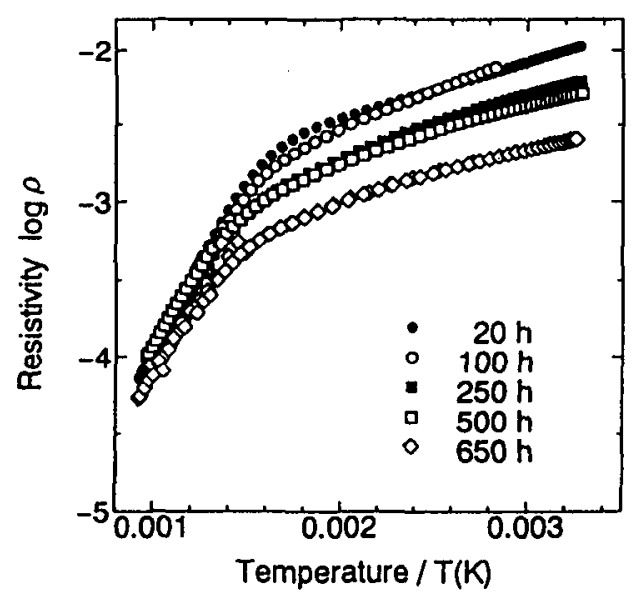

Fig. 3 Relation between $\log \rho$ and $1 / \mathrm{T}$ of $\mathrm{Fe}-$ 66. 7atxSi samples ball-milled for various hours and hot-pressed at $900^{\circ} \mathrm{C}$ for $30 \mathrm{~min}$. 
処理して $\beta$ 相化する速度に比して、MGの $\beta$ 相化促 進効果が極めて大であることが分かる.

Fig. 3に20-650hr MG した後、900 ${ }^{\circ} \mathrm{C} て ゙ 30 \mathrm{~min}$ ホットプレスした試料の比抵抗の対数 $\log \rho$ と1/Tの 関係を示す．図より明らかなように、温度の上昇に ともなって、抵抗が減少しており半導体特性を示し ている. 比抵抗の值は、MG時閒が長くなる程減少 するか、低温での減少が顥著で、高温になると殆ど 差はなくなる．また、500K以下と700K以上とで傾き の異なる2つの直線からなっており、それぞれの領 域で伝導機構が巽なることを示している．500K以下 では不純物伝導領域、700K以上では固有伝導领战で あると考えられる。8)

MG 時間20 650 hrの訪料の熱起電力の温度低存 性をFig.4に示す．熱起電力Qは、いずれの埸合も 正の值を取り、 $\mathrm{p}$ 型半導体であることを示している. 無添加の $\beta-\mathrm{FeSi} 2$ はFe灙度の增大にともなってn型 からP型に装化すると報喈されており、5）本实験で 得られた試料の組成か下e過剩側に変化しているもの と考えられる。熱起電力の值は500 600Kで最大值 をとり、温度の上昇にともなって急激に隇少する傾 向を示すが、最大值を比較すると、MG時閒 $100 \mathrm{hr}$ で最大となった後、MG时間の増大にともなって急 激に低下する，一方、熱電材料の性能の目安となる 出力因子Q2/ $\rho$ は、Fig. 5に見られるように、

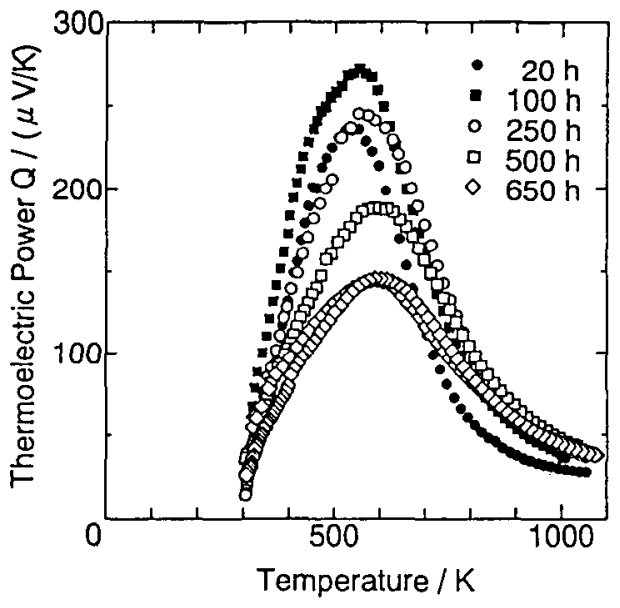

Fig. 4 Temperature dependence of thermoelectric power of $\mathrm{Fe}-66.7 \mathrm{at} \% \mathrm{Si}$ ball-milled for various hours and hot-pressed at $900^{\circ} \mathrm{C}$ for 30 min.



Fig. 5 Temperature dependence of power factor of Fe-66. 7at\$Si ball-molled for various hours and hot-pressed at $900^{\circ} \mathrm{C}$ for $30 \mathrm{~min}$.

MG 時間250hrで最大倠をとった後、MG時間の增 大にともなって再び低下する。

ホットプレス試料のSEM推察およびEPMA分析の結果、 $\beta$ 相中には $\varepsilon$ 相が微紐に分散しており、そのサイズ はMG時間が脣くなるほど微細となる。

Fig. 6に試料中のFe含有率のMGによる変化を示 す. $M G$ 時間の增大に伴ってFe含有率は急激に增大 し、650 hrでは38at\%にも達する。 $\beta$ 相は組成幅の 栖めて狭い金属間化合物であるから、化学量論組成 を越えたFe分が全て $\varepsilon$ 相を形成すると仮定して計算 すると、 $\varepsilon$ 相の体積案は約30\%なりSEM篗察結果と ほほ一致する。



Fig. 6 Fe content changes during MG. 
$\beta$ 半導体相中に $\varepsilon$ 金属相が分散している場合の伝 導率 $\sigma$ は、その体積率から次式により計算され 3. 9)

$$
\sigma=1 / \rho=(1-f) / \rho(\beta)+\mathrm{f} / \rho(\varepsilon)
$$

ただし、試料中の $\varepsilon$ 相の体程率をf、 $\varepsilon$ 及び $\beta$ 机の 比抵抗をそれぞれ $\rho(\beta)$ 及び $\rho(\varepsilon)$ とする. $\rho(\varepsilon)$ $=2.2-2.5 \times 10^{-6} \Omega \mathrm{m} \mathrm{m}^{10)} 、 \rho(\beta)=5.0-10.0 \times 10^{-3}$ $\Omega \mathrm{m}$ と ${ }^{11)} 、 \rho(\varepsilon) の$ 力がかなり小さいので、 $\varepsilon$ 机の 含有率が增大すると比抵抗が小さくなることは容易 に理解できる。

一方、 $\beta$ 相中に $\varepsilon$ 相が分散している場合の熱起電 力が次式によって変化すると仮定して計算すると、

$$
\mathrm{Q}=\mathrm{Q}_{\beta}(\mathrm{l}-\mathrm{f})+\mathrm{Q}_{\varepsilon} \mathbf{f}
$$

出力因子 $\mathrm{Q}^{2} / \rho$ の值は、Fig.7のように、 $\mathrm{f}=0.3$ で 最大值を取った後、急激に低下寸る傾向を示し、実 験結果(Fig. 5)と概略一致した傾向を示しているが、 $\varepsilon$ 相の果たす効果についてはさらに詳細な検討が必 要である。ただし、 $\beta$ おとび $\varepsilon$ 相の熱起電力をそ れぞれQ $\left.\beta=250 、 Q_{\varepsilon}=2.6 \mu \mathrm{V} / \mathrm{K} と し 、 8\right) \beta$ 相およ び $\varepsilon$ 相の比抵抗值には、上記の平均值 $\rho(\varepsilon)=$ 2. $2 \times 10^{-6} \Omega \mathrm{m} 、 \rho(\beta)=10.0 \times 10^{-3} \Omega \mathrm{m}$ を採用した。

性能指数は $Z=Q^{2} / \rho \cdot \kappa て ゙$ 表わされるので、性 能指数を增大させる上で、熱伝導率 $\kappa$ を減少させる ことが極めて重要な因子である。 MG後、ホット プレスした試料の室温における熱伝導率の $\mathrm{MG}$ 時間 依存性をFig. 8に示す。熱伝導率はMG時間の畦大 にともなって急激に減少し、MG 時間500hrでは約 $7 \mathrm{~W} / \mathrm{m}$ ・KとMGを施していない試料の場命 $(11 \mathrm{~W} / \mathrm{m}$ ・ K)より約35\%も減少しており、M Gが熱伝導率の低 下に極めて有効であることを示している。これは、 $M G に よ っ て ~ \beta$ 相の結晶稙が著しく微細になり、粒 界におけるフォノンの散乱による効果であると考え られる。一方、図中の矢印で示したように、MG

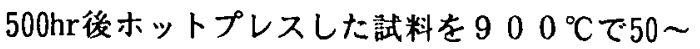
100hr焼鈍すると、焼鈍時間の增大にともなって熱 伝導率が再び増大する。これは焼鈍による結晶粒 成長によるものと考えられる。したがって、高性 能の $\beta-\mathrm{FeSi}_{2}$ 系熱電材料を得るためには、MGや MAによって $\beta$ 相の結晶粒を微綀にすると同時に、 $\varepsilon$ 相など異相をさらに微細に分散することによって、 結晶粒成長を抑制することが必要であることが分か る。

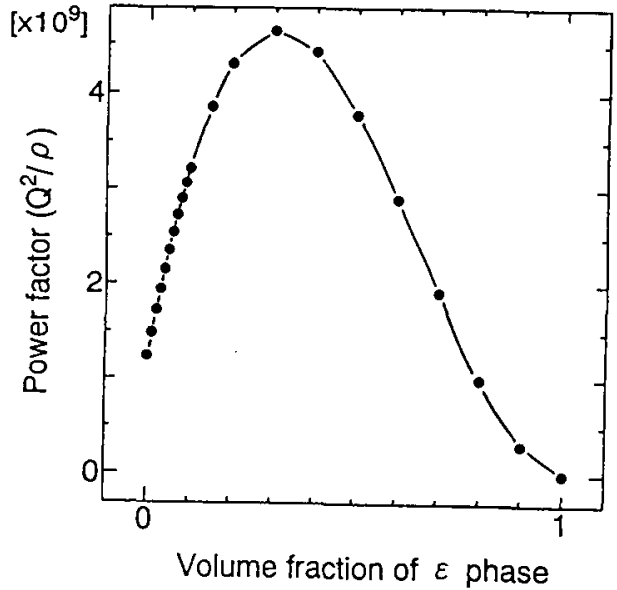

Fig. 7 Estimated power factor for $\beta-\mathrm{FeSi}_{2}$ containing various volume fraction of $\varepsilon$-phase.

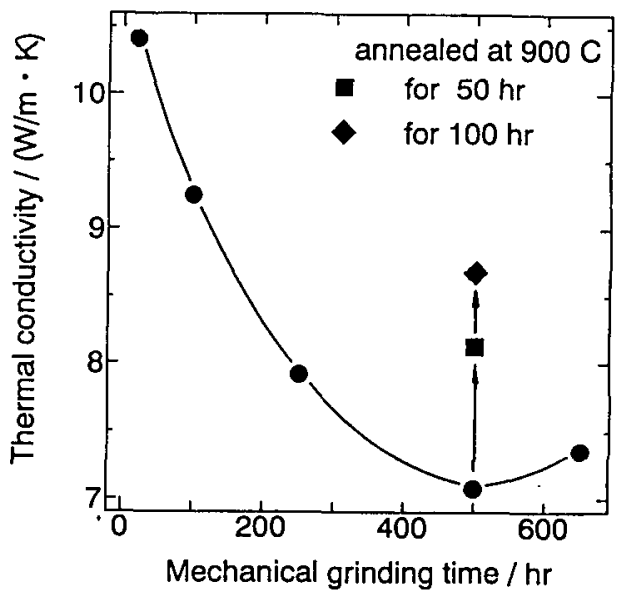

Fig. 8 Effect of MG time and annealing on the thermal conductivity of Fe-66.7at\%Si ballmilled for various hours and hot-pressed at $900^{\circ} \mathrm{C}$ for $30 \mathrm{~min}$. 
4 緹语

本研究で得られた結果を要約すると以下の通りで ある。

1)アーク溶解後、粉砕した試料は $\alpha-\mathrm{Fe}_{2} \mathrm{Si}_{5}$ 相と $\alpha$ $\mathrm{FeSi}$ 相からなり、MG时閌の堵大にともなって、そ れらのX線のピークは著しくブロードとなるが、 $\beta$ 相は形成しない。しかしながら、MGを施した粉 末の場合には、900 $\mathrm{C} て ゙ 30$ minホットプレスするだけ で容易に $\beta$ 相化し、溶解法で作製した $(\alpha+\varepsilon)$ 相 の試料を熱処理によって $\beta$ 相を形成する速度に比較 して極めて速い。

2) MGを施した後、ホットプレスした試料中には、 $\varepsilon$ 金属相の微細な粒子が分散しており、比抵抗を著 しく低下させる。一方、得られた焼秙体試料の熱 起電力は、MG100hrで最大值を取った㣪急激に減 少するが、比抵抗が著しく娍少するため、出力因子 Q2/ 2 はMG時間250hrは最大值を示す。したがって、 出力因子を向上させるためには、 $\varepsilon$ 相など比抵抗の 小さい粒子を適当量微細に份散させることが必要で あると考えられる。

3） MG 時間の増大に伴って、 $\beta$ 相の結晶粒が著し く微細になるため、熱伝導率は急激に減少するが、 焼鈍による結晶粒成長により再び増大する。した がって、高性能 $\beta$-FeSi2系熱電材料を得るには、 MG PMA法で結晶粒を微細化することが極めて有
效であるが、思相の分散などにより結晶䊀成長を抑 制することが必要である。

文献

1)上村欣一、西田梨刃：熱電半察体とその応用、 日刊工菜新䦕社、(1988)

2)金属問化合物部会最終報尛苗: 第 3 編、機能材料 に関する調查報告書、金属䦦化合物部会(1990)

3)西田勲男：金属、10(1984)34.

4)T. Kojima, M. Okamoto and I. Nishida : Proc. 5th Int. Conf. Thermoelectric Energy Conv., March(1984), 56.

5)西田勲思：材料科学、15(1978), 72.

6)M. M. Ibrahim, N. Afifiy, Y. K. Hafiz and

M. A. Mahmoud :J. Phys. Chem. Sol ids, 51(1990)253.

7)永井 宏、飯田純生、前田純志、勝山茂、真島

一彦: 粉体および粉末冶金、40(1993), 332.

8）坂田民雄、西田勲男：日本金属学会会報、 15(1976), 11.

9)西田勲男、岡本昌明、大越恒雄、磯田幸宏 : 金材技砄報告、11(1990), 145 .

10)V. S. Neshpor and G. V. Samsonov: Dokl. Akad. Nauk. SSSR, 134(1960), 1337.

11)U. Birkholz and J. Schelm:Phys. Status Solidi, 27(1965), 413. 